\title{
Exploring mediating factors in the association between parental psychological distress and psychosocial maladjustment in adolescence
}

\author{
Christelle Roustit • Eric Campoy • Basile Chaix • \\ Pierre Chauvin
}

Received: 25 February 2009/Accepted: 8 January 2010/Published online: 3 February 2010

(C) The Author(s) 2010. This article is published with open access at Springerlink.com

\begin{abstract}
Parental psychopathology is associated with increased psychosocial maladjustment in adolescents. We examined, from a psychosocial perspective, the association between parental psychological distress and psychosocial maladjustment in adolescents and assessed the mediating role of psychosocial covariates. This is a cross-sectional survey and the setting include representative sample of Quebec adolescents in 1999. The participants of the study include 13- and 16-year-old children $(N=2,346)$ in the Social and Health Survey of Quebec Children and Adolescents. The main outcome measures are internalizing disorders, externalizing disorders, substance use, and alcohol consumption. For statistical analysis, we used structural equation modeling to test for mediation. Internalizing and externalizing disorders were significantly associated with parental psychological distress, but not substance use or alcohol consumption. The higher the parental distress, the higher the risk of adolescent mental health disorders. The association between parental psychological distress and internalizing disorders was mediated by
\end{abstract}

C. Roustit $(\bowtie) \cdot$ B. Chaix · P. Chauvin

INSERM U707, Research Group on the Social Determinants of Health and Healthcare, UPMC, Univ Paris 06,

27 rue Chaligny, 75012 Paris, France

e-mail: christelle.roustit@inserm.fr

C. Roustit

Laboratoire EA2027, Univ Paris 08, 93526 Saint-Denis, France

E. Campoy

DRM, CREPA (CNRS, UMR7088), Université Paris-Dauphine, 75016 Paris, France

P. Chauvin

Department of Public Health, AP-HP, Hôpital Saint-Antoine,

75012 Paris, France adolescent self-esteem, parental emotional support and extrafamilial social support. As for externalizing disorders, these variables only had an independent effect. In conclusion, A family's well being is a necessary condition for psychosocial adjustment in adolescence. Beyond the psychiatric approach, psychosocial considerations need to be taken into consideration to prevent negative mental health outcomes in children living in homes with distressed parents.

Keywords Adolescent health - Parental distress . Psychosocial factors · Epidemiology · Population survey

\section{Introduction}

The psychiatric literature suggests that parental depression has a negative impact on children's psychological development and, consequently, on their psychosocial adjustment $[5,15,16]$. Children from homes with affectively ill parents are more likely to exhibit general functional impairments, increased guilt, and interpersonal difficulties $[18,44]$, which lead to negative mental health outcomes. The existing literature has described this association in patient samples or population surveys from a clinical perspective [3, 24]. Moreover, longitudinal studies have shown that the disadvantages associated with growing up in a home with an affectively ill parent persist over time [29, 42].

Depression, which is considered part of a psychological distress continuum or a discrete diagnostic entity, is a highly prevalent disorder in the entire adult population [23]. However, rates of adult depressive disorders vary greatly according to their definition and, consequently, to their identification, either from high scores on self-reporting questionnaires or from clinical interviews [11], but in 
both cases, a strong relationship between parental depression and negative child mental health outcomes (both depressive disorders and/or non-affective disorders) has been observed [4, 31]. However, what is far less known is the distribution of adult psychological distress in the entire population and its impact on children in terms of psychosocial maladjustment beyond any clinical psychiatric diagnosis.

Two main theoretical models are used to explain the link between parental depression and psychosocial maladjustment in children: the transmission model and the contextual model. The transmission model argues that parenting practices are affected by parental depression [33]. The consequences of depression-related maladaptive parenting are negative or unresponsive attitudes and behaviors toward the child, which lead to insecure attachment, poor emotional self-regulation and poor social interaction. Contingent responding may result in suboptimal cognitive and affective development in children. The contextual model, on the other hand, considers that external factors, including socioeconomic conditions and negative life events, could explain both parental depression and child maladjustment. In previous studies, poverty and high levels of stressful life events associated with maternal depression were also significant predictors of adjustment problems in children [6]. From an integrative perspective, Essex et al. [17] showed that family socioeconomic status (SES) defines different pathways to children's later symptom severity. Being born into a low- or middle-SES family sets up early experiences, starting in infancy, involving exposure to chronic maternal distress. This, in turn, sets up a developmental pathway for the child that results in higher levels of behavioral dysregulation during the preschool years and subsequent social and academic impairments. Being born into a high-SES family may be protective, as evidenced by mean differences in the symptom severity levels of the two SES subgroups. In such families, the link between parental depression and child maladjustment can be explained by a different mediational chain, which begins prenatally with family histories of psychopathology transmitted across generations. Considered genetic risk indicators, familial psychiatric disorders could be used to identify a subset of children at a risk for psychopathology [42]. In this connection, genetic epidemiological studies provide arguments for the genetic hypothesis [39]. Numerous studies of offspring of parents with major depressive disorders have shown the familial nature of depression, but also the higher risk of psychopathological disorders in these children [30, 41]. Lastly, there is an interplay between the parents' mental health and that of their children, which makes a solely unidirectional understanding too simplistic [20].

In 1994, the Institute of Medicine (US) published a report encouraging the development of research on the treatment and prevention of psychopathology in children and adolescents at high risk for disorders because of parental affective illness [26]. One promising avenue that was suggested for promoting children's well being was to investigate mediational pathways between parental psychopathology and child disorders. However, most of the studies conducted on this topic are limited for two reasons: first, most of them have focused on parental major depressive disorders, and few of them have documented the consequences of parental distress in the community or a non-referred population and second, and this is an epistemological concern, researchers have failed to incorporate into their models psychological and social factors or family functioning variables, which makes a mediational model less fruitful.

In the present study, our objective was to investigate the association between parental psychological distress and child internalizing disorders, externalizing disorders, substance use and alcohol consumption. Then, controlling for socioeconomic factors, we sought to determine whether the following three aspects-adolescent selfesteem, parental emotional support, and extrafamilial social support-were associated with these outcomes and whether they mediate the association between parental psychological distress and adolescent psychosocial maladjustment.

\section{Methods}

Subjects

This study was based on the data from the Social and Health Survey of Quebec Children and Adolescents (ESSEAQ), which was conducted in 1999 by the Institut de la Statistique du Québec (ISQ, Quebec Statistics Institute, Quebec, Canada). The survey process was described in a previous report [2]. This survey was based on a two-stage cluster random sample of 2,346 13- and 16-year olds (and their 1983 parents) enrolled in school. Data were collected by means of two self-administered questionnaires, one completed by the children at school, the other by their parents at home. The entire survey protocol had been approved by the Quebec Statistics Institute Ethics Committee. Written informed consent was obtained from all the adolescents, their parents, and the boards for the participating schools.

Assessment of psychosocial maladjustment disorders

Four indicators of psychosocial maladjustment were studied: internalizing disorders, externalizing disorders, substance use and alcohol consumption. 
Internalizing disorders were defined as the presence of a high level of psychological distress and/or a suicide attempt or suicidal thoughts. The psychological distress index was evaluated by a 14-item scale measuring the occurrence of symptoms associated with depression, anxiety, reactive aggressiveness and cognitive disorders during the week preceding the survey. The scale's internal and external validity had been demonstrated by Deschenes in a Quebec adolescent population in previous surveys [14]. A high level of psychological distress corresponds to the highest quintile of this 0-100 scale. Suicidal behavior was defined as at least one suicide attempt or suicidal thoughts during the previous 12 months [9].

The externalizing disorder variable was defined by the presence or absence of any behavioral disorders and/or oppositional attitudes. These indicators were defined on the basis of the Diagnostic Statistical Manual [1]. Behavioral disorders implied the occurrence of at least three disturbing behaviors (out of a list of 15 items) during the previous 6 months. These items, completed by the adolescents, concerned assault or fighting, cruelty to animals, damaging property, theft or fraud, or a serious violation of the law. To gauge the adolescents' oppositional attitudes, the questions in this survey used DSM IV criteria. The questions, which consisted of eight statements, were completed by the parent that knew the adolescent best. An oppositional behavior index was created by summing the "entirely true" responses to these statements. A level of 4 or more was required for an adolescent to be considered as presenting with an oppositional behavior. Lastly, binary variables indicated the presence/absence of internalizing and externalizing disorders.

Substance use was defined as the use of marijuana or hashish, cocaine, solvents, hallucinogenics, unprescribed medications and/or other illicit drugs more than once during the child's lifetime [8]. Alcohol consumption was reported as an intake frequency during the previous 12 months and was divided into three categories (never or only tried, once a month or less, more than once a month).

Assessment of parental distress, covariates and socioeconomic factors

Parental psychological distress was the main independent variable. The psychological distress index was adapted from the self-administered version of the Psychiatric Symptom Index [25]. This index was used to evaluate the frequency of symptoms relating to depression, anxiety, anger and cognitive problems within the previous 7 days (frequency was rated on a 4-point scale, where $1=$ never and $4=$ very often). The total-score range was $0-100$. The higher the score, the more severe the parent's psychological distress symptoms. The Cronbach's $\alpha$, a measure of internal consistency, ranged from 0.72 to 0.89 for the subscales and the total score [32]. We divided the parental distress variable into three categories using the score distribution tertiles.

The covariates were the following variables: self-esteem and school-related variables (academic performance, school self-confidence and aspirations, school atmosphere), parental interaction (parental emotional support, parental control) and adolescent social support (with the exclusion of that from the parents). We performed a preliminary bivariate analysis to use only those covariates associated both with parental psychological distress and adolescent psychosocial maladjustment. These covariates were adolescent self-esteem, parental emotional support and extrafamilial support. Self-esteem was evaluated by the Rosenberg self-esteem scale, using three levels (low, moderate, high) [40]. Parental emotional support was assessed separately for each parent by the adolescent using the scale developed by Schaefer and validated in a previous Canadian study $[13,37]$. In the present study, the reference period was the previous month, and the score, which ranged from 0 to 16 , was divided into three categories (low, moderate, high). Social support was evaluated by a shortened version of the Social Support Rating Scale of Cauce et al. [10]. The initial scale examined the usefulness of parents, siblings, peers, teachers or other persons in providing social support to the adolescent. After excluding the parent-related item, we constructed a dichotomous variable based on the distribution of the adolescents. Half of them received support from three or more sources, the other half from fewer than three sources (3 sources of support/two or fewer sources).

Lastly, in addition to age and gender, the adjustment variables included the following socioeconomic factors: parental education (primary, secondary, vocational training, junior college, university), annual family income per consumer unit (very poor, poor, low middle, high middle, rich), food insecurity (yes/no), and parental employment status (at least one parent employed, both parents unemployed).

Statistical analyses

The first step of the analysis consisted in examining the associations between parental distress and the four maladjustment outcomes. We estimated binary or multinomial logistic regression models for each of these outcomes while controlling for gender and socioeconomic variables. The models were estimated for each age group separately (13-year olds and 16-year olds), then for the entire sample, with an additional adjustment for age.

Second, we tested the associations between parental distress and each of the following covariates, self-esteem, parental interaction and social support, using binary or 
multinomial logistic regression models adjusted for age, gender and SES.

Lastly, we used structural equation modeling to test for mediation. The variables significantly associated with parental distress in step 2 were introduced into a path analysis. We compared the direct and indirect effect of parental distress on internalizing disorders, then on externalizing disorders after introducing these variables into the models as mediators in the association between parental distress and adolescent's mental health disorders. The following fit indices were used to assess the model fit: the root-mean square error of approximation (RMSEA) and the normed-fit index (NFI). Statistical significance was defined as a $P<0.05$. As described in a previous ISQ report [2], the data in the original dataset were weighted to adjust for selection probabilities, to reduce non-response bias and to adjust for population distribution. SPSS ${ }^{\circledR} 12.0$ and LISREL 8.8 procedures were used to perform the statistical analyses.

\section{Results}

Association between parental psychological distress and adolescent psychosocial maladjustment

Table 1 presents the odds ratios (ORs), adjusted for gender, age and SES variables, for the associations between parental psychological distress and psychosocial maladjustment in adolescents estimated by logistic regression models. The results confirm that adolescents living with a highly psychologically distressed parent were more likely to exhibit internalizing disorders and externalizing disorders. Moreover, higher the level of parental psychological distress, higher is the risk of adolescent psychosocial maladjustment. In addition, this effect was found for both types of disorders in the 16-year age group and for externalizing disorders only in the 13-year age group (an interaction term indicated a stronger effect of parental distress in the older adolescent group for internalizing disorders, $P<0.05$ ). Lastly, parental distress was not found to be associated with substance use or alcohol consumption (results not shown).

Consequences of parental psychological distress

Table 2 shows the independent effect of living with a distressed parent on adolescent self-esteem, parental emotional support and extrafamilial social support. The logistic regression models were adjusted for age, gender and socioeconomic variables. The greater the parental psychological distress, lower is the adolescent's selfesteem and social support. Only the highest level of parental distress had a negative effect on parental emotional support.

Table 1 Adjusted odds ratios and 95\% confidence intervals for associations between parental distress and adolescent psychosocial maladjustment variables

\begin{tabular}{|c|c|c|c|c|c|c|}
\hline & \multicolumn{3}{|l|}{ Internalizing disorders } & \multicolumn{3}{|l|}{ Externalizing disorders } \\
\hline & $\begin{array}{l}\text { Both } \\
\text { OR }(95 \% \mathrm{CI})\end{array}$ & $\begin{array}{l}\text { Psychological } \\
\text { distress } \\
\text { OR (95\% CI) }\end{array}$ & $\begin{array}{l}\text { Suicide attempt } \\
\text { OR }(95 \% \mathrm{CI})\end{array}$ & $\begin{array}{l}\text { Both } \\
\text { OR }(95 \% \mathrm{CI})\end{array}$ & $\begin{array}{l}\text { Conduct } \\
\text { disorders } \\
\text { OR }(95 \% \mathrm{CI})\end{array}$ & $\begin{array}{l}\text { Oppositional } \\
\text { attitudes } \\
\text { OR }(95 \% \mathrm{CI})\end{array}$ \\
\hline \multicolumn{7}{|l|}{ Entire group } \\
\hline \multicolumn{7}{|c|}{ Parental psychological distress } \\
\hline Low & 1 & 1 & 1 & 1 & 1 & 1 \\
\hline Moderate & $1.46 *(1.07-2.00)$ & $1.27(0.93-1.73)$ & $1.98(0.89-4.37)$ & $1.60 * *(1.20-2.13)$ & $1.45^{*}(1.07-1.97)$ & $2.00 * *(1.22-3.28)$ \\
\hline High & $1.85 * * *(1.36-2.52)$ & $1.78 * * *(1.31-2.42)$ & $2.64 *(1.21-5.74)$ & $2.06 * * *(1.54-2.76)$ & $1.68 * *(1.24-2.29)$ & $3.41 * * *(2.12-5.48)$ \\
\hline \multicolumn{7}{|c|}{ 13-year age group } \\
\hline \multicolumn{7}{|c|}{ Parental psychological distress } \\
\hline Low & 1 & 1 & 1 & 1 & 1 & 1 \\
\hline Moderate & $1.20(0.80-1.80)$ & $1.01(0.67-1.52)$ & $1.73(0.57-5.19)$ & $1.43(0.95-2.16)$ & $1.18(0.76-1.84)$ & $2.21 *(1.11-4.38)$ \\
\hline High & $1.38(0.92-2.07)$ & $1.34(0.89-2.00)$ & $2.53(0.88-7.27)$ & $2.00 * *(1.33-3.00)$ & $1.55 *(1.00-2.41)$ & $4.45 * * *(2.33-8.50)$ \\
\hline \multicolumn{7}{|c|}{ 16-year age group } \\
\hline \multicolumn{7}{|c|}{ Parental psychological distress } \\
\hline Low & 1 & 1 & 1 & 1 & 1 & 1 \\
\hline Moderate & $2.03 * *(1.22-3.37)$ & $1.84 *(1.10-3.05)$ & $2.28(0.71-7.33)$ & $1.84 * *(1.22-2.77)$ & $1.77 * *(1.16-2.71)$ & $1.85(0.90-3.80)$ \\
\hline High & $2.80 * * *(1.70-4.60)$ & $2.72 * * *(1.65-4.47)$ & $2.77(0.86-8.96)$ & $2.22 * * *(1.46-3.37)$ & $1.87 * *(1.20-2.90)$ & $2.51 *(1.23-5.12)$ \\
\hline
\end{tabular}

Controlling for age, gender and the family's socioeconomic status in the entire group and for the latter two parameters in each age group separately

CI confidence interval 
Table 2 Adjusted odds ratios and 95\% confidence intervals for associations between parental distress and covariates

\begin{tabular}{|c|c|c|c|c|c|}
\hline & \multicolumn{2}{|c|}{ Self-esteem (Ref. = high) } & \multicolumn{2}{|c|}{ Parental emotional support (Ref. $=$ high) } & \multirow{2}{*}{$\begin{array}{l}\text { Social support } \\
\text { (Ref. }=3 \text { sources) } \\
2 \text { sources or less } \\
\text { OR }(95 \% \text { CI })\end{array}$} \\
\hline & $\begin{array}{l}\text { Moderate } \\
\text { OR }(95 \% \text { CI })\end{array}$ & $\begin{array}{l}\text { Low } \\
\text { OR }(95 \% \mathrm{CI})\end{array}$ & $\begin{array}{l}\text { Moderate } \\
\text { OR }(95 \% \mathrm{CI})\end{array}$ & Low & \\
\hline \multicolumn{6}{|c|}{ Parental psychological distress } \\
\hline Low & 1 & 1 & 1 & 1 & 1 \\
\hline Moderate & $1.50 * *(1.14-1.97)$ & $1.66 * *(1.16-2.39)$ & $1.11(0.86-1.44)$ & $1.18(0.72-1.94)$ & $1.27 *(1.01-1.61)$ \\
\hline High & $1.72 * * *(1.28-2.0 .32)$ & $2.73 * * *(1.89-3.95)$ & $1.54 * *(1.17-2.03)$ & $2.06 * *(1.26-3.35)$ & $1.36 *(1.07-1.74)$ \\
\hline
\end{tabular}

Controlling for age, gender and the family's socioeconomic status in the entire group

CI confidence interval

${ }^{\text {a }}$ Parental support excluded

$* P<0.05 ; * * P<0.01 ; * * * P<0.001$

Structural equation models

Figure 1 shows that low self-esteem $(\beta=-0.44$, $P \leq 0.001)$, a lack of parental emotional support $(\beta=-$ $0.14, P \leq 0.001)$ and a lack of social support $(\beta=-0.17$, $P \leq 0.001)$ were significantly associated with internalizing disorders. The fit indices are the following: the root mean square error of approximation was within the acceptable range (RMSEA $=.059$ ) and the normed fit index was 0.96 . An examination of the path coefficients shows that the standardized total effect (0.17) of parental distress on internalizing disorders is significant $(P \leq 0.001)$, but the strength of the direct association decreases and is not significant $(\beta=-0.05, P>0.05)$ in the full model. The total effect is significantly mediated by self-esteem, parental emotional support and social support (standardized indirect effect $=0.11 ; P \leq 0.001$ ).

Figure 2 shows that low self-esteem $(\beta=-0.10$, $P \leq 0.01)$, a lack of parental emotional support $(\beta=-0.18$,
$P \leq 0.001)$ and a lack of social support $(\beta=-0.07$, $P \leq 0.05)$ were also significantly associated with externalizing disorders. The fit indices are the following: the root mean square error of approximation was within the acceptable range (RMSEA=.059) and the normed fit index was 0.95 . However, the total effect $(0.21)$ of parental distress on externalizing disorders $(P \leq 0.001)$ was only partially due to the potential mediating variables (standardized indirect effect $=0.05 ; P \leq 0.001$ ). The direct effect of parental distress on externalizing disorders remains high and significant $(\beta=-0.16, P \leq 0.001)$.

\section{Discussion}

The primary objective of our study was to examine the association between parental psychological distress and psychosocial maladjustment in adolescents. The results confirm such an association for internalizing and
Fig. 1 Graphical display of the path analysis model. Mediating model of the association between parental psychological distress and internalizing

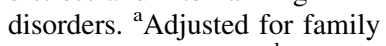
socioeconomic status. ${ }^{\mathrm{b}}$ Adjusted for age and gender $* P<0.05$; $* * P<0.01 ; * * * P<0.001$

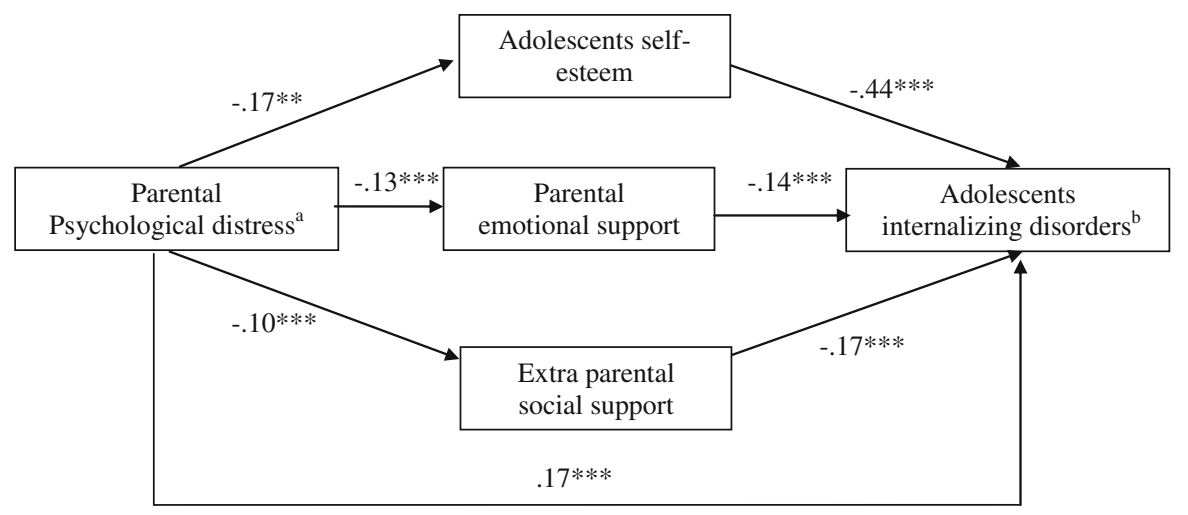

Direct standardized effect of parental psychological distress $=.17 * * *$

Total indirect effect of parental psychological distress $=(-.17 \mathrm{x}-.44)+(-.13 \mathrm{x}-.14)+(-.10 \mathrm{x}-.17)=.11 * * *$ Percentage of parental psychological distress effect mediated by adolescents self-esteem, parental emotional support and extra parental social support $=.11 /(.11+.17)=39 \%$ 
Fig. 2 Graphical display of the path analysis model. Mediating model of the association between parental psychological distress and externalizing

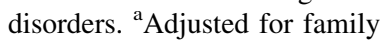
socioeconomic status. ${ }^{\mathrm{b}}$ Adjusted for age and gender $* P<0.05$; $* * P<0.01 ; * * * P<0.001$

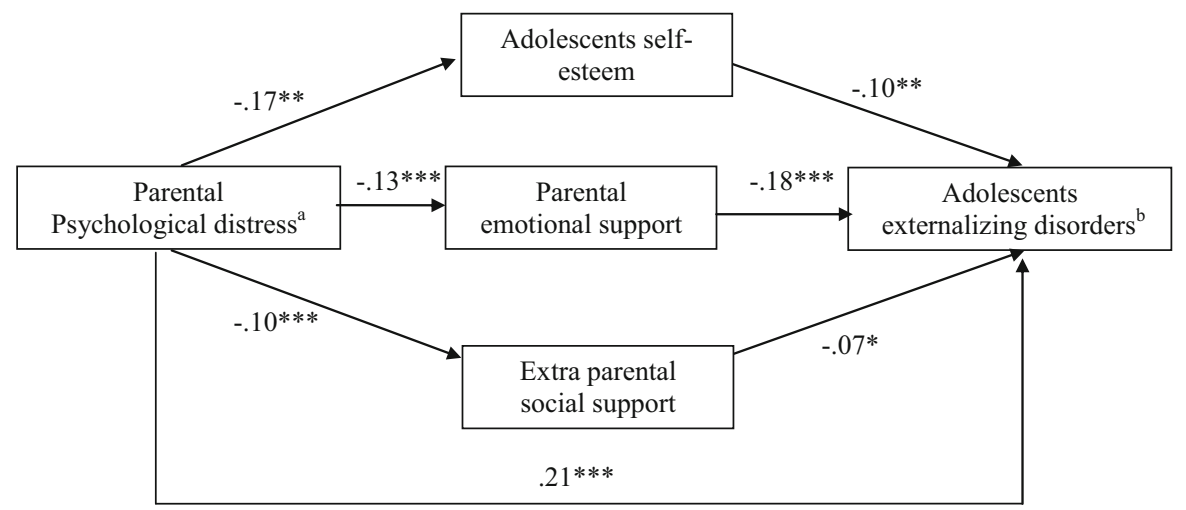

Direct standardized effect of parental psychological distress $=.21 * * *$

Total indirect effect of parental psychological distress $=(-.17 \mathrm{x}-.10)+(-.13 \mathrm{x}-.18)+(-.10 \mathrm{x}-.07)=.05^{* * *}$

Percentage of parental psychological distress effect mediated by adolescents self-esteem, parental emotional support and extra parental social support $=.05 /(.05+.21)=19 \%$ externalizing disorders. Population studies (i.e., studies not involving referred populations) are rare, and they have used different indicators of parental psychopathological disorders, which precludes comparisons with our research. Nonetheless, our results are concordant with general observations demonstrating maladaptive outcomes in children living with a psychologically disordered parent. Interestingly, we found a gradient in the association between parental distress and adolescent maladaptive outcomes. Higher the parental distress, higher is the risk of adolescent disorders.

Our study found that three variables were associated with both parental distress and adolescent psychosocial maladjustment. First, self-esteem was strongly associated with internalizing and, to a lesser extent, externalizing disorders. Self-esteem is a crucial factor in a child's development. This psychological feature is developed by the child interacting with bonding figures. It determines the quality of an individual's relationship with him or herself, a relationship which requires contact with and feedback from others, and, most importantly, from parental figures. Parental distress is associated with negative or disengaged interactions resulting in a child's dysfunctional cognitions about him or herself, e.g., low self-esteem, and dysfunctional cognitions about others, which leads to depressive reactions or impaired social functioning [21].

Second, parental emotional support had an independent effect on internalizing and externalizing disorders. In a family process model, Cummings et al. [12] hypothesized that parenting practice difficulties due to distress hamper parental support, which, in turn, affects the child's adjustment. In our study, the results might be concordant with the developmental model hypothesis, according to which children draw on both internal and external resources to meet age-salient objectives through adaptation processes of emotional and behavioral organization in response to phase-specific developmental issues. Thus, adaptive outcomes at each phase of development reflect a transactional process between the child and his or her environment. The role and function of child caregiving are also essential for ensuring coherence and continuity in a child's adaptation. According to this model, a lack of parental emotional support, which is closely aligned with attachment, could introduce a potential source of discontinuity into a child's ability to adapt to his or her environment [28]. In addition, in a social epidemiological perspective, Wyman et al. [43] demonstrated that competent, responsive caregiving was not only a direct, proximal predictor of a child's positive adjustment, but also a mediator of contextual resources, such as parental education and health. Lastly, these dynamic interactions affect how children interpret adversity, how they respond to it, and whether the adversity is resolved, recurs or leads to further adversities over time. This could explain the association we found between a lack of adolescent social support (our third variable) and both parental distress and internalizing or externalizing disorders.

The secondary objective of our study was to identify a mediating effect of selected variables in the association between parental distress and adolescent psychosocial maladjustment. We found that self-esteem, parental emotional support and extrafamilial social support had a mediating effect in the association between parental distress and internalizing disorders, and had an independent effect on externalizing disorders. Preventing both types of disorders in a psychologically disordered family require a better knowledge of the transactional processes in family relationships according to an ecological and intergenerational 
model. A few studies in developmental psychology have emphasized the structure of family relationships as the main determinant of future psychopathological disorders [27]. Interparental violence [34, 35], negative parenting [38] or childhood parentification [19] have been shown to be factors that determine the developmental pathway from parental distress to child mental health disorders. In an adolescent-centered approach, helping develop adolescents' positive feelings of self-esteem and self-efficacy should boost their self-confidence and help them respond actively to life's challenges [36]. In a family centered care perspective, interventions designed to increase the parents' provision of emotional support to their child may contribute to the latter's sense of security that his or her parents are a reliable source of nurturance and such security is also a feature of other social relationships that assist children in coping with stressful events that cause upheavals in other areas of their lives.

Several limitations of the present study should be mentioned. First, the psychological distress index was based on the symptoms that had occurred during the previous 7 days, not during the parent's adult lifetime. Features of distress, such as the age of onset (and the corresponding age of the child answering the questionnaire) or whether it was recurrent or not, were not among the information requested. Yet, these characteristics also determine the quality of child-parent interaction and, consequently, the risk of maladjustment [22]. Second, the ESSEAQ survey had a cross-sectional design, which leaves unresolved the question of the direction of the estimated effects. The association between parental distress and negative disorders in adolescents may be due to reciprocal effects. Third, we did not introduce into our model childcentered characteristics other than self-esteem, such as temperament, intelligence and self-system variables (beliefs about self-worth, control and future expectations). Lastly, many studies show that exposure to parental distress is significantly associated with interparental violence, which, in turn, sets the stage for child maltreatment [7]. Unfortunately, the hypothesis that child maltreatment could be a confounding factor in the association between parental distress and internalizing and/or externalizing disorders could not be tested in our study.

In conclusion, our preliminary findings confirm the importance of better understanding the consequences of a parent's ill-being on his or her child's mental health. They also confirm the need for public health policies aimed at preventing negative mental health outcomes in adolescents by preventing and addressing parental distress.

Acknowledgments We thank the Quebec Statistics Institute (Quebec, Canada) for providing the dataset from the Social and Health Survey of Quebec Children and Adolescents. We gratefully thank Lucie Gingras, Head of the Centre d'Accès aux Données de Recherche de l'Institut de la Statistique du Québec (CADRISQ, Montreal, Canada).

\section{Conflict of interest statement None.}

Open Access This article is distributed under the terms of the Creative Commons Attribution Noncommercial License which permits any noncommercial use, distribution, and reproduction in any medium, provided the original author(s) and source are credited.

\section{References}

1. American Psychiatric Association (1994) Diagnostic and statistical manual of psychiatry of mental disorders, 4th edition (DSMIV). American Psychiatric Association, Washington

2. Aubin J, Lavallee C, Camirand J, Audet N (2002) Enquête sociale et de santé auprès des enfants et des adolescents québécois 1999 [1999 Social and Health Survey of Children and Adolescents in Quebec], Institut de la Statistique du Québec, Quebec

3. Beardslee WR, Keller MB, Lavori PW, Klerman GK, Dorer DJ, Samuelson H (1988) Psychiatric disorder in adolescent offspring of parents with affective disorders in a non referred sample. J Affect Disord 15:313-322

4. Beardslee WR, Keller MB, Lavori PW, Staley JE, Sacks N (1993) The impact of parental affective disorder on depression in offspring: a longitudinal follow-up in a nonreferred sample. J Am Acad Child Adolesc Psychiatry 32:723-730

5. Beardslee WR, Versage EM, Gladstone TR (1998) Children of affectively ill parents: a review of the past 10 years. J Am Acad Child Adolesc Psychiatry 37:1134-1141

6. Belle D (1982) Lives in stress. Sage, Beverly Hills

7. Belsky J, Vondra J (1989) Lessons from child abuse: the determinants of parenting. In: Cichetti D, Carlson V (eds) Child maltreatment: theory and research on the causes and consequences of child abuse and neglect. Cambridge University Press, Cambridge, pp 153-202

8. Botvin GJ, Baker E, Renick NL, Filazzola AD, Botvin EM (1984) A cognitive-behavioral approach to substance abuse prevention. Addict Behav 9:137-147

9. Brener ND, Collins JL, Kann L, Warren CW, Williams BI (1995) Reliability of the youth risk behavior survey questionnaire. Am J Epidemiol 141:575-580

10. Cauce AM, Mason C, Gonzales N, Hiraga Y, Liu G (1994) Social support during adolescence: methodological and theoretical considerations. In: Nestmann F, Hurrelmann K (eds) Social networks and social support in childhood and adolescence. DeGruyter, New-York, pp 89-110

11. Coyne JC, Gotlib IH (1983) The role of cognition in depression: a critical appraisal. Psychol Bull 94:472-505

12. Cummings EM, Davies PT (1999) Depressed parents and family functioning: interpersonal effects and children's functioning and development. In: Joiner T, Coyne JC (eds) The interactional nature of depression. American Psychological Association, Washington, pp 299-327

13. Deschesnes M (1992) Styles de vie des jeunes du secondaire en Outaouais. Le vécu psychosocial des élèves du secondaire dans la région de l'Outaouais. Rapport final [Lifestyles of high school youths in the Ottawa Valley. The psychosocial experience of high school students in the Ottawa valley, Final Report]. Département de santé communautaire, Hull

14. Deschesnes M (1998) Etude de la validité et de la fidélité de l'indice de détresse psychologique de Santé Québec (IDPSQ-14) 
chez une population adolescente [Assessment of the validity and reliability of Santé Québec's psychological distress index (IDPSQ-14) in an adolescent population]. Can Psychol 39:288-298

15. Dodge KA (1990) Developmental psychopathology in children of depressed mothers. Dev Psychopathol 26:3-6

16. Downey G, Coyne JC (1990) Children of depressed parents: a integrative review. Psychol Bull 108:50-76

17. Essex MJ, Kraemer HC, Armstrong JM, Boyce WT, Goldsmith HH, Klein MH, Woodward H, Kupfer DJ (2006) Exploring risk factors for the emergence of children's mental health problems. Arch Gen Psychiatry 63:1246-1256

18. Forehand R, McCombs A (1988) Unraveling the antecedentconsequence conditions in maternal depression and adolescent functioning. Behav Res Ther 26:399-405

19. Fitzgerald MM, Schneider RA, Salstrom S, Zinzow HM, Jackson J, Fossel RV (2008) Child sexual abuse, early familial risk and childhood parentification: pathways to current psychosocial adjustment. J Fam Psychol 22:320-324

20. Ge X, Conger RD, Lorenz FO, Shanahan ME, Glen H (1995) Mutual influences in parent and adolescent psychological distress. Dev Psychol 31:406-419

21. Goodman SH, Gotlib I (1999) Risk for psychopathology in the children of depressed mothers: a developmental model for understanding mechanisms of transmission. Psychol Rev 106:458-490

22. Hammen C, Brennan PA (2003) Severity, chronicity, and timing of maternal depression and risk for adolescent offspring diagnoses in a community sample. Arch Gen Psychiatry 60:253-258

23. Hasin DS, Goodwin RD, Stinson FS, Grant BF (2005) Epidemiology of major depressive disorder: results from the national epidemiologic survey on alcoholism and related conditions. Arch Gen Psychiatry 62:1097-1106

24. Hirshfeld-Becker DR, Biederman J, Henin A, Faraone SV, Dowd ST, De Petrillo LA, Markowitz SM, Rosenbaum JF (2006) Psychopathology in the young offspring of parents with bipolar disorder: a controlled pilot study. Psychiatry Res 145:155-167

25. Ilfeld FW (1976) Further validation of a psychiatric symptom index in a normal population. Psychol Rep 39:1215-1228

26. Institute of Medicine (1994) Reducing risks for mental disorders: frontiers for preventive intervention research. National Academy Press, Washington DC

27. Jacobvitz DB, Bush NF (1996) Reconstructions of family relationships: parent-child alliances, personal distress, and selfesteem. Dev Psychol 32:732-743

28. Masten AS, Coatsworth JD (1998) The development of competence in favorable and unfavorable environments: lessons from research on successful children. Am Psychol 53:205-220

29. Nomura Y, Wickramaratne PJ, Warner V, Mufson L, Weissman MM (2002) Family discord, parental depression, and psychopathology in offspring: ten-year follow-up. J Am Acad Child Adolesc Psychiatry 41:402-409

30. Olino TM, Pettit JW, Klein DN, Allen NB, Seeley JR, Lewinsohn PM (2008) Influence of parental and grandparental major depressive disorder on behaviour problems in early childhood: a three-generation study. J Am Acad Child Adolesc Psychiatry 47:53-60
31. Pilowsky DJ, Wickramaratne PJ, Rush AJ, Hughes CW, Garber J, Malloy E, King CA, Cerda G, Sood AB, Alpert JE, Wisniewski SR, Trivedi MH, Talati A, Carlson MM, Liu HH, Fava M, Weissman MM (2006) Children of currently depressed mothers: a STAR*D ancillary study. J Clin Psychiatry 67:126-136

32. Préville M, Boyer R, Potvin L, Perrault C, Légaré G (1992) La détresse psychologique : détermination de la fiabilité et de la validité de la mesure utilisée dans l'enquête Santé Québec [Psychological distress: assessment of the reliability and validity of the index used in the Santé Québec survey]. Research report submitted to Santé Québec. Quebec City, Santé Québec

33. Richters J, Weintraub S (1990) Beyond diathesis: Toward an understanding of high-risk environments. In: Rolf J, Masten AS, Cichetti D, Nuechterlein KH, Weintraub AS Risk and protective factors in the development of psychopathology. Cambridge University Press, New York, pp 67-96

34. Roustit C, Chaix B, Chauvin P (2007) Family breakup and adolescents' psychosocial maladjustment: public health implications of family disruptions. Pediatrics 120:e984-e991

35. Roustit C, Renahy E, Guernec G, Lesieur S, Parizot I, Chauvin P (2009) Exposure to interparental violence in childhood and psychosocial adjustment in adult's life-course: advocacy for an early prevention. J Epidemiol Commun Health 63:563-568

36. Rutter M (1985) Resilience in the face of adversity: protective factors and resistance to psychiatric disorder. $\mathrm{Br} \mathrm{J}$ Psychiatry 147:598-611

37. Schaefer ES (1965) Children's report of parental behavior: an inventory. Child Dev 36:413-424

38. Shelton KH, Harold GT (2008) Interparental conflict, negative parenting, and children's adjustment: bridging links between parents' depression and children's psychological distress. J Fam Psychol 22:712-724

39. Sullivan PF, Neale MC, Kendler KS (2000) Genetic epidemiology of major depression: review and meta-analysis. Am J Psychiatry $157: 1552-1562$

40. Vallières EF, Vallerand R (1990) Traduction et validation canadienne-française de l'échelle de l'estime de soi de Rosenberg [French-Canadian translation and validation of the Rosenberg Self-Esteem Scale]. Int J Psychol 25:305-316

41. Weissman MM, Wickramaratne P, Nomura Y, Warner V, Pilowsky D, Verdeli H, Pilowsky DJ, Grillon C, Bruder G (2005) Families at high and low risk for depression: a 3-generation study. Arch Gen Psychiatry 62:29-36

42. Weissman MM, Wickramaratne $P$, Nomura $Y$, Warner V, Pilowsky D, Verdeli H (2006) Offspring of depressed parents: 20 years later. Am J Psychiatry 163:1001-1008

43. Wyman PA, Cowen EL, Work WC, Hoyt-Meyers LA, Magnus KB, Fagen DB (1999) Caregiving and developmental factors differentiating young at-risk urban children showing resilient versus stress-affected outcomes: a replication and extension. Child Dev 70:645-659

44. Zahn-Waxler C, Kochanska J, Krupnick J, McKnew DH (1990) Patterns of guilt in children of depressed and well mothers. Dev Psychol 26:51-59 